January 2004

\title{
Young learners of modern foreign languages and their transition to the secondary phase: a lost opportunity?
}

Allison Bolster

University of Bristol, United Kingdom

Christine Balandier-Brown

University of Bristol, United Kingdom

Pauline Rea-Dickins

Aga Khan University, pauline.rea-dickins@aku.edu

Follow this and additional works at: http://ecommons.aku.edu/eastafrica_ied

Part of the English Language and Literature Commons, and the Junior High, Intermediate, Middle School Education and Teaching Commons

\section{Recommended Citation}

Bolster, A., Balandier-Brown, C., Rea-Dickins, P. (2004). Young learners of modern foreign languages and their transition to the secondary phase: a lost opportunity?. The Language Learning Journal, 30(1), 35-41.

Available at: http://ecommons.aku.edu/eastafrica_ied/42 


\section{Young learners of modern foreign languages and their transition to the secondary phase: a lost opportunity?}

\section{Allison Bolster , Christine Balandier-Brown \& Pauline Rea-Dickins}

To cite this article: Allison Bolster, Christine Balandier-Brown \& Pauline Rea-Dickins (2004) Young learners of modern foreign languages and their transition to the secondary phase: a lost opportunity?, The Language Learning Journal, 30:1, 35-41, DOI: 10.1080/09571730485200211

To link to this article: http://dx.doi.org/10.1080/09571730485200211

巴nublished online: 06 Aug 2007.

Submit your article to this journal $\sqsubset$

山ll Article views: 1045

Q View related articles $\longleftarrow$

Citing articles: 12 View citing articles 4 


\title{
Young learners of modern foreign languages and their transition to the secondary phase: a lost opportunity?
}

\author{
Allison Bolster, Christine Balandier-Brown and Pauline Rea-Dickins \\ University of Bristol
}

\begin{abstract}
Following publication of the National Languages Strategy on 18 December 2002 the teaching of foreign languages (FL) in the primary school is again high on the agenda in England as in other parts of Europe. Research has shown in the past (Burstall et al., 1974) that an early start in $\mathrm{FL}$ does not necessarily result in any long-term advantage in terms of proficiency. However, the above study also draws other conclusions, less widely reported, which remain significant. These include insufficient liaison between primary and secondary schools, lack of continuity in foreign language learning across phases, inadequate training of teachers, and a lack of differentiation by MFL secondary teachers. This article describes a small-scale research project which took place between April 2002 and May $2003^{1}$. It sought to identify some of the main issues of transition from the perspective of the learners themselves, their foreign language teachers, heads of $F L$ departments and head teachers at primary and secondary level. A complex and somewhat contradictory picture emerges from this study. On the one hand, there are many positive findings such as the enjoyment of languages and openness to other cultures and languages in the primary phase, greater oral fluency and confidence of learners when transferring to the secondary phase and enthusiasm shown for early language learning (ELL) by teachers in the primary and the secondary phase. On the other hand, opportunities which exist for building on primary language learning are largely wasted.
\end{abstract}

\section{INTRODUCTION}

In England the teaching of FL in the primary school is high on the agenda, as it is in other parts of Europe. Within the wider European context, young primary children begin to learn a foreign language between the ages of 8 and 10 , and primary school teachers in some countries, such as France, Germany, Austria, Greece and Italy, are expected as part of their professional responsibilities to be able to teach a foreign language. This level of activity has exerted an influence on the thinking of politicians in Britain. On 25 March 1999, the DfEE announced a new government initiative to promote and develop the provision and quality of FL learning in the primary school, which would be co-ordinated through the Centre for Information on Language Teaching and Research (CILT). Two specific actions were taken, the establishment of a National Advisory Centre on Early Language Learning (NACELL), to be based at CILT, and the creation of a Good Practice Project (GPP) in which bids would be invited from LEAs and schools to receive a small amount of funding to start or support primary pilot projects.

More recently, the National Languages Strategy, published on 18 December 2002, introduced the primary entitlement as one of its cornerstones, declaring (p. 15):

Every child should have the opportunity throughout key stage 2 to study a foreign language and develop their interest in the culture of other nations. They should have access to high quality teaching and learning opportunities, making use of native speakers and E-learning. By age 11 they should have the opportunity to reach a recognised level of competence on the Common European Framework and for that achievement to be recognised through a national scheme. The key stage 2 language learning programme must include at least one of the working languages of the European Union and be delivered at least in part in class time.

The context of the debate about teaching FL at primary school and the issues that it raises have therefore undergone considerable changes. On the one hand, FL is no longer compulsory in the later stages of secondary school and, on the other, it has become an entitlement for pupils at key stage 2. There is potential for FL provision, already diverse, to become more so, making it increasingly difficult to provide a smooth transition from primary to secondary and to ensure continuity for pupils. If FL teaching is to be coherent across phases, a number of fairly complex considerations need to be borne in mind. The challenge of ensuring a smooth transition centres on decisions across a wide range of dimensions, all of which have a fundamental effect upon pupil progress, attainment and motivation. These include: the aims and objectives of foreign language learning; the appropriateness of various pedagogical

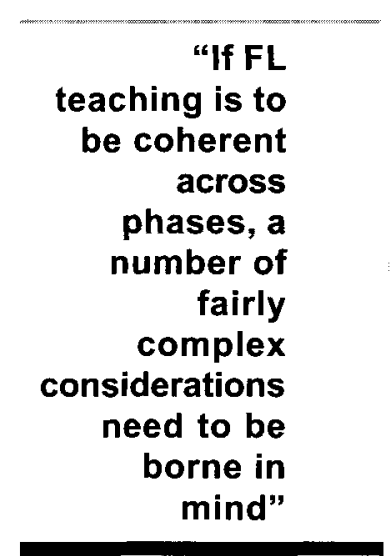

Address for correspondence: Allison Bolster Graduate School of Education University of Bristol 35 Berkeley Square Bristol BS8 1JA email: a.bolster@bristol.ac.uk 
approaches; the question of who should teach foreign languages at primary school; local constraints in terms of teacher expertise; language preference; assessment and record keeping; the impact of diversification at secondary school; and, last but by no means least, liaison between primary and secondary schools.

\section{THE RESEARCH}

\section{AIMS}

Our research set out to gain insights into some of the problems which arise as young learners of FL cross the divide between primary and secondary cultures, and to explore possible strategies to overcome them. The main research questions were as follows:

1. What are the factors that those involved hold to be important in relation to transition from primary to secondary school for young learners of FL?

2. What impact do the factors identified in (1) have on children's achievements and enjoyment of language learning at key stage 3 ?

3. What strategies do schools have in place to deal with these factors and what measures might be taken to lessen any negative impact?

While these are 'big' questions, this small-scale exploratory study sought only to identify some of the main issues surrounding transition from the different perspectives of the main stakeholders: the learners themselves, their foreign language teachers, heads of modern languages and the schools' head teachers.

\section{METHODOLOGY}

A case-study approach was adopted, targeting one primary school and five secondary schools to which it is a feeder school. The study gathered data from all the main stakeholders, thereby allowing a variety of viewpoints to emerge.

The research involved interviews and small focus-group discussions, designed to achieve triangulation by ensuring that each interview covered the same range of questions, regardless of the age or status of the interviewee. A semistructured approach was adopted for the interviews so as to allow interviewees the maximum opportunity to express their views and to raise possible strategies in relation to research question 3.

A focus discussion group of $4 / 5$ students each from Years 7 and 8 (each group composed of two pupils with primary French experience and two without) was carried out in each secondary school, along with a sample of six Year 6 primary school students.

All interviews and discussions were taped and later transcribed.

\section{SCHOOL PROFILES}

The primary school

The primary school was chosen for its impressive track record in teaching French to all pupils in the final two years of key stage 2 . The most recent OFSTED inspection (20 November 2000) reported "standards in French achieved by 11 year-olds (as) above average" and that, "the teaching of French is very good" (p. 4).

The school is very large in comparison with most primary schools. At the time of the study there were 410 pupils on roll, $84 \%$ of whom were of white ethnicity with the remainder largely of Asian descent. Fifteen percent of the pupils are identified by the school as having special educational needs, although almost all of these pupils are likely to achieve nationally expected levels of attainment by the time they are 11 years of age. Three percent of pupils are eligible for free school meals, which is below the national average.

French is taught to Years 5 and 6 for one session per week. There are two classes in each year group, each class (of approximately 30 pupils) is split in half for the French lesson, and each halfgroup has $\mathbf{3 0}$ minutes' instruction. This regular teaching 'slot' makes the school a rarity among maintained primary schools. Lack of time for regular FL instruction is part of the overall shortage of curriculum time in primary schools, which tend to concentrate on the core National Curriculum subjects of English, maths and science in order to raise pupils' performance in National Curriculum level tests.

\section{The secondary schools}

The LEA in which the schools are situated has one of the highest numbers of independent secondary schools in the country, and for a variety of reasons they are often a favoured choice of middle-class parents within the city boundaries; they were certainly the preferred destination for the majority of the pupils from the primary school in the study. Four of the five secondary schools targeted were selective independent schools, of which one (School A) was mixed, two were for boys only (Schools B and E) and one was for girls only (School C). It is worth noting that all the independent schools had, by the nature of their intake, a very high number of feeder primary schools - as many as 55 in the case of School A! The only state secondary school visited (School D) was a large and sought-after mixed 11-18 comprehensive school in a favoured catchment area not far from the primary school.

\section{THE FINDINGS}

\section{TRANSITION-LINKS BETWEEN PRIMARY AND SECONDARY SCHOOLS}

Despite these apparently favourable conditions, one of the major disappointments in our findings was the virtually total lack of liaison between primary and secondary phases. At a whole-school level, there were visits by the senior management team (SMT) of the secondary to the primary schools - although often on a rolling basis due to the large number of feeder primaries. However, any 
information passed on, either verbally between head teachers or in the form of KS2 SATs results, concentrated on core NC subjects such as English and maths or on pupils with special educational needs. There was no evidence that FL was ever reported upon, either in terms of kind and quality of experience, or in relation to individual student performance; nor was there evidence of visits or links between the secondary FL departments - as opposed to the SMT - and the primary schools. Equally, neither the primary school co-ordinator who taught in School D, nor the secondary teacher who also taught in the junior section of School A, had sufficient influence to be able to co-ordinate the curriculum between their two institutions. Although head teachers at both the primary school and School $\mathrm{C}$ were aware of the need for closer links to be forged, no successful formula had yet been found. Staff in both phases expressed concern over the lack of a formal means to pass on information, such as a standardised reporting system. The LEA is thought to be considering such a scheme, but none is in place at the time of writing, which has implications for the quality of transition in all subjects, not just FL.

\section{ORGANISATIONAL ISSUES}

Curriculum, methodology and staffing in the primary school - the primary perspective

The primary school has been offering FL provision for a long time. When the current head teacher, a linguist, took up his position, he maintained and strengthened the position of FL in the school for the following reasons:

- Children in KS1 and KS2 are more willing to take a FL on board;

- Popularity with parents;

- Helping Year 6 to transfer to Year 7.

Staff in the primary school were well aware that, despite the exciting initiatives they had introduced, many questions had yet to be addressed. There was a lack of agreement on fundamental issues, e.g. about the objectives of formal language teaching at primary school. As a result, the school had a very diverse system for early language learning (ELL) in place focused on cultural and language awareness, language skills (Spanish), and foreign language learning (French). The Spanish taught by the class teacher was done on an ad hoc basis, with no real scheme of work, while there was very little time allocation for the formal teaching of French, i.e. 30 minutes per week per half-group. Uncertainty also existed about whether to give priority to listening and speaking or whether grammatical structures should be introduced. There was no formal assessment for Year 6 ELL pupils at the time of the study and, although the head teacher acknowledged the difficulty of providing accurate reports of individual levels of achievements without using formal assessment, it was felt that assessment might 'kill' the fun at primary.
Some of these uncertainties about the curriculum and its focus stemmed from a need for training, provided by the school and by outside agencies, for ELL teachers and co-ordinators. The primary French teacher in the study felt isolated in her role, hence her problems in co-ordinating syllabi within and between the two institutions. The head teacher had considered the possibility of having FL teaching delivered by a visiting secondary teacher, while another option that had been considered was the possibility of language training for the ELL primary teachers being undertaken by specialists from the secondary sector, but, although such schemes do exist, limitations on secondary teacher availability were obvious. Not all secondary teachers have either the interest or the pedagogical expertise to teach children at the primary phase, as confirmed by the secondary specialist in School $A$, who had been delegated to teach part-time in Year 6 of her school, but was not altogether comfortable with the different methodology required. Overall, the primary school reported that the difficulty of finding staff qualified and able to teach FL at the primary level had various implications, including that of limiting diversity in choice of language formally taught. French had been chosen as it was a language with which most primary teachers were felt to be more confident and because of parental choice.

Primary curriculum, methodology and staffing the secondary perspective

Staff interviewed in the secondary schools all had, in principle, a very positive attitude towards the value of ELL. They saw it as particularly advantageous in terms of capitalising on younger learners' greater linguistic and attitudinal openness to other cultures and their language systems. However, significant reservations were expressed about the practical implications, particularly within the present UK context with its overall shortage of teachers qualified to teach FL. They expressed many of the same concerns about delivery of ELL as their primary colleagues quoted above. They had reservations, too, about a perceived lack of specification in content and aims; variety of methodology (some exclusively grammar-based, some exclusively oral/aural); lack of contact time; use of non-specialist staff; and a lack of (reported) assessment. Above all, given the very large number of feeder primaries from which they drew, it was the immense variety in kind, frequency and length of the prior ELL experience of their pupils which was perceived as posing the greatest problems for FL teaching in the secondary schools.

\section{Continuity and differentiation at the transition phase}

Given the lack of liaison across phases reported above, it is unsurprising that continuity of FL curriculum into the secondary schools in the study was virtually non-existent; and this was even predicted by staff at the primary school, who recognised the need for some form of

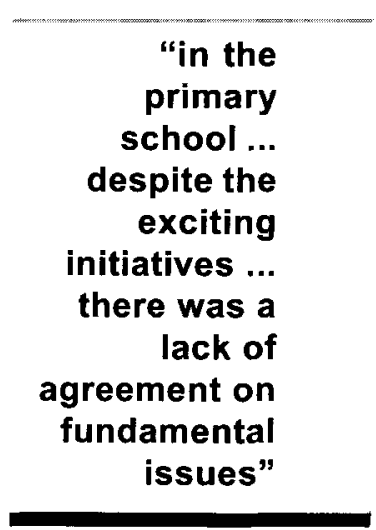


differentiation at the secondary phase in favour of those with ELL. All the FL secondary teachers were in favour of setting, and complained of the constraints imposed by competing timetabling needs. Although most secondary head teachers, particularly those in schools $\mathrm{A}$ and $\mathrm{B}$, expressed the desire to allow pupils with ELL to enter a 'fasttrack' set to GCSE - possibly continuing with a further language at KS4, or going on to AS level in their first foreign language - this was simply a hope for the future. There was no differentiation for groups of children with prior ELL experience in any secondary school in the study. All such pupils had to "start again from scratch".

We have no facility for... small groups... if we could put some of them together we could have a slower path or an accelerated path or whatever... but we have no flexibility to do that at all and it is a major curriculum problem. (School C, HOD)

Even in the selected secondary schools in the study, the majority of Year 7 pupils were 'beginners' in language learning. Therefore, the main concern of the FL staff was not to reassure those with ELL that their prior language experience was of value, but to reassure those pupils without ELL that they were at no disadvantage. At best, this entailed (unusually) sending out some pupils for extra practice with the FL assistant or, more frequently, using those with prior knowledge of the language as models or "spring-boards" for the rest of the class, until such time as their 'advantage' (usually in terms of acquired vocabulary) was eroded. The overriding priority, as evidenced in our data, was to ensure that all pupils were "at the same stage by Christmas" $(A, T)$.

\section{EFFECTS ON PUPILS' MOTIVATION AND ACHIEVEMENT BETWEEN KS2 AND KS3}

Pupil achievement - teachers' perspective

As there was no formal assessment in the primary school in the study, standards of achievement there at KS2 were impossible to judge. However, secondary teachers of FL were unanimous in identifying many short-term, non-assessed advantages of ELL in terms of pupils' confidence and fluency in speaking, good accents and good listening comprehension skills, and many concurred that such good habits often persisted into KS4 and beyond (with the rider that faulty linguistic habits such as mispronunciation of words, once ingrained, were difficult to change). However, they also expressed the concern that some pupils with this early advantage could be over-confident and occasionally lack written accuracy. This perception of a lack of written accuracy may be a contributory factor to the secondary teachers' unanimous conviction that ELL gave no long-term, assessed advantage to pupils, even in examinations as early as at the end of Year 7. However, we might question exactly what skills and competences such tests set out to assess.
Pupil achievement - pupils' perspective

Secondary pupils' perceptions of the value of their ELL experience mirrored the views of their teachers to a remarkable extent (see above), all perceiving it as irrelevant to their long-term achievement in languages. Their teachers' view that the highest academic achievers in FL were usually those without an ELL background had clearly often been reiterated, no doubt to encourage later starters, particularly in School B. Witness the following extract from two School B Year 7 pupils with no prior language experience, who were discussing whether or not the pupil who had come 'top' of the French examination the previous year had prior language experience (our italics):

A: Well the boy who came top at the end of the year was -

B: Only did half a year -

A: He'd done half a year which was just a club. Apparently it happens every year.

\section{Pupil motivation}

Their teachers' unanimous policy of downplaying and tending to ignore any prior ELL experience, however well-intentioned, seems likely - in our view - to have contributed to the somewhat disillusioned attitude of a certain number of the secondary school pupils with an ELL background interviewed. This was more marked in Year 8, as witnessed by the following boy from School B: "We would have done better to spend the time on extra maths and English".

Early failure was seen as likely to replicate itself as early success. As another Year 8 pupil with ELL (this time a girl from School C) remarked: "I've never liked French. Just don't like it".

A number of encouraging findings do, however, also exist. The secondary head teachers, particularly in Schools A and B, felt that primary pupils, with their lack of self-consciousness and capacity for enthusiasm, were far more likely to respond to foreign language instruction favourably than would adolescents. This perception of openness to learning languages at the primary phase seems to be borne out by our findings; and some of these attitudes persisted at the secondary phase. In the primary school it was noticeable that pupils had positive attitudes towards France and other countries, and they reported enjoying their language experience; a number of the pupils with ELL maintained these attitudes at secondary school. Early success was also seen as bound to continue in secondary school, while a large number of secondary pupils - particularly at the still-enthusiastic Year 7 stage saw many advantages, some of them unexpected, in their prior experience of learning a foreign language. Many of them had enjoyed their primary experience, seeing it as 'fun', with less academic pressure than at secondary school:

It was fun 'cos you were looking forward to the games at the end... 
I liked the speaking. I liked the accents. (School C, Year 7, Pupils A and B, prior experience)

Rather than feeling 'bored' by covering known vocabulary and topics a second time at secondary school, pupils felt this gave them an advantage, as it was easier to assimilate the language a 'second time around'. They also felt it was a social advantage, a boost to self-confidence when entering on a new phase of their education, not to have to face a completely new subject. Most encouragingly, many also had enlightened attitudes towards diversification, and were keen to learn a number of languages other than French (Spanish and Italian were frequently mentioned, but suggestions ranged as far as Russian and Urdu). Others were keen to travel, as with two Year 7 girls with ELL from School C who had already decided where to go for their Gap Year abroad!

\section{SOME CONCLUSIONS: A LOST OPPORTUNITY?}

A complex and somewhat contradictory picture emerges from this study. On the one hand, there are some very positive findings: pupil enjoyment of languages and openness to other cultures and their languages in the primary phase, often accompanied by greater fluency, better accents and oral and aural confidence (reported in the teacher interviews), do sometimes persist in the long-term. Moreover, the commitment and enthusiasm shown for ELL by teachers in the primary school found an echo, theoretically at least, among both specialists and head teachers at the secondary phase: "I've got a feeling - I don't quite know where it comes from - that ... (ELL) can't but be a good thing." (head teacher, School C)

In view of this theoretical rapport between the primary and secondary teachers, and of the highly favourable conditions for FL learning which obtained in all the schools studied, it seems all the more regrettable that in this particular case study the clear opportunity which existed for building on that prior ELL was largely being wasted.

It is to be hoped that primary schools such as School $\mathrm{F}$ in the study will become increasingly aware of the growing amount of advice and guidance open to them. CILT has produced some excellent publications on introducing and implementing ELL. The recently produced Scheme of Work for KS2 FL (QCA, 2004) will be particularly useful if primary teachers are to provide that common foundation of early language experience which secondary FL teachers believed to be so vital for cross-phase continuity. Increasing numbers of examples of good practice are becoming available online from the GPP (www.cilt.org.uk), - particularly the NACELL Best Practice Guide (www.nacell.org) - and informative meetings with Regional Support Groups (RSGs) for ELL take place, for everyone interested to attend, in all fourteen Comenius Centres in England. Bridging Units between Years 6 and 7 for FL are now being developed, such as that produced by South Gloucestershire LEA. More and more re-training courses for primary generalists wishing to teach FL are becoming available too, often from institutes of higher education, although no one can deny the cost to both schools and individuals, both financially and in terms of time. There is also the possibility of employing foreign language assistants to work alongside primary generalists, helping them to deliver the target language, and capable of adding a rich cultural dimension to ELL - although this, too, involves expenditure. It should perhaps be noted here that the National Languages Strategy mentions the use of native speakers resident in the UK in helping deliver ELL, but in the authors' opinion the implications of such a scheme would be enormous, not least in terms of such individuals' need for training both in primary and in FL pedagogy. The provision of Outreach Training for primary generalists, whether by primary and secondary advanced skills teachers (ASTs) in FL, specialist language teachers from language colleges, or LEA advisers (where available) will have to expand, not only to help primary schools inaugurate ELL, but also to support them in its long-term development and embedding into the primary curriculum. It also seems clear that primary schools such as the one in our study will need to provide some sort of report on the ELL experiences of their pupils at the transition phase; some primary schools are beginning to use the European Languages Portfolio (Liverpool LEA and Richmond upon Thames, for example), and the government is reportedly to start piloting a new national recognition scheme for languages (the National Languages Ladder, see www.dfes.gov.uk/ languages) in September 2004.

There is, then, a need for further action at the primary phase. However, it appears that the somewhat depressing confirmation, in this admittedly small-scale study, of the findings of Burstall et al. back in 1974 - that an early start in FL does not necessarily lead to any long-term advantage in terms of proficiency - stems from the same fundamental cause: a lack of continuity and provision for differentiation at the secondary phase. As former heads of languages in comprehensive schools ourselves (BalandierBrown and Bolster), we are acutely aware of the difficulties caused when individual pupils arrive in Year 7 with a very different language profile from the majority of the class. There are, of course, a number of ways in which differentiation might be effected within the classroom, but what became apparent in our study was the overriding wish on the part of all the FL secondary teachers for a more flexible timetable, allowing for those with and without ELL to be taught in separate sets. However,

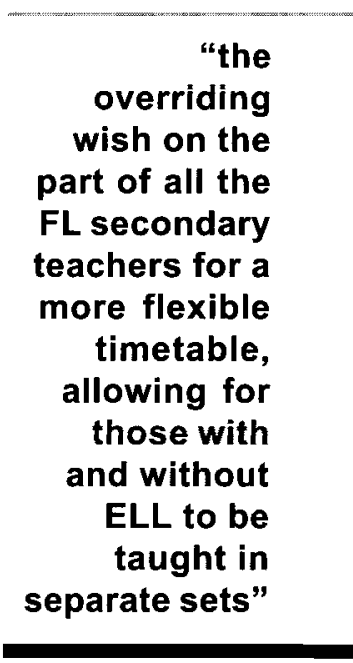


in spite of their apparent openness (reported above) to the idea of pupils with ELL to 'fast-track' to GCSE in Year 9, and despite the large number of pupils with ELL in their intake, the head teachers of these secondary schools were not yet using their executive power to ensure that the requisite curricular changes were put into place.

Following the publication of the National Languages Strategy in 2002, it seems to us that over the next few years the circumstances faced by the secondary schools in the study are likely to apply to other UK secondary schools too. Everincreasing numbers of Year 7 pupils will be entering secondary school with considerable ELL experience behind them. Are secondary head teachers and FL departments going to rise to the challenge, and grasp the wonderful opportunity for building on that prior knowledge which is being offered, or is this to become another wasted initiative as with the Nuffield Pilot project all those years ago?

\section{SUMMARY OF RECOMMENDATIONS}

1. Greater standardisation of primary FL curriculum:

- Agreement on common aims (language awareness, or, as seems likely, language learning);

- Co-ordination of syllabus content, language skills and methodology - e.g. using the KS2 Framework for FL, teaching FL literacy as well as oracy;

- Common duration of study - e.g. the whole of KS2;

- The use of a common framework of assessment, such as the National Languages Ladder.

2. Greater provision of training for existing primary generalists, through, for example:

- E-learning;

- Funding for continuing professional development (CPD);

- Outreach training.

3. Greater provision of support in terms of time and funding for primary generalists and FL coordinators in primary schools:

- To enable attendance at meetings of Regional Support Groups (RSGs);

- To enable the use of foreign language assistants (FLAs) - or, possibly, other native speakers resident in UK, if adequately trained - alongside primary generalists.

4. The provision of far greater numbers of primary teachers trained to teach FL, through, for example:

- Further expansion of numbers in initial teacher training (ITT) and the Graduate Trainee Programme (GTP) for primary teachers of FL;

- Re-training programmes (possibly through CPD) for existing secondary specialists in FL.
5. Collaboration and continuity between clusters of primary and secondary schools, particularly as regards:

- Agreement on a common rationale for ELL;

- Choice of languages taught: continuity or diversification?;

- Agreeing a method for passing on information, especially about pupil assessment.

6. A national engagement, by secondary head teachers as well as heads of secondary FL departments, and as ELL provision becomes more and more widespread, for:

- Recognition of prior learning for those pupils with ELL;

- Timetabling provision for differentiation between pupils with and without ELL.

\section{NOTES}

1 We are indebted to the primary and secondary schools concerned for their ready co-operation in our research.

This research was supported by the University of Bristol Small Grants Fund.

We would like to acknowledge Katie Scott, University of Bristol for her work in reviewing the literature and developing the bibliography for this report.

\section{REFERENCES}

Blondin, C., Candelier, M., Edelenbos, P., Johnstone, R., Kubanek-German, A. and Taeschner, T. (1998) Foreign Languages in Primary and Pre-School Education: A review of recent research within the European Union. London: Centre for Information on Language Teaching and Research

Burstall, C., Jamieson, M., Cohen, S. and Hargreaves, M. (1974) Primary French in the Balance. Windsor: NFER

CILT (2003) NACELL Best Practice Guide www.nacell.org DfEE (1999) Handbook for Primary Teachers in England. Key Stages 1 and 2: Guidelines for MFL at KS2 (nonstatutory). London: DfEE/QCA

DfEE (1999) The National Curriculum for England: Modern foreign languages. London: DfEE/QCA

DfES (2002) The Green Paper 14-19: Extending opportunities, raising standards. London: DfES

DfES (2002) Languages for All: Languages for life - a strategy for England. London: DfES

DfES (2003) Excellence and Enjoyment: A strategy for primary schools. London: DfES

DfES (2003) Framework for Teaching Modern Foreign Languages: Years 7, 8 and 9. London: DfES

Doyé, P. and Hurrell, A. (eds) (1997) Foreign Language Learning in Primary Schools. Strasbourg: Council of Europe

Driscoll, P. and Frost, D. (eds) (1999) The Teaching of Modern Foreign Languages in the Primary School. London: Routledge

Edelenbos, P. and Johnstone, R. (1996) "European MLPS research: past, present, and future. Towards a wider community." In Edelenbos, P. and Johnstone, R. (eds) Researching Languages at Primary School: Some European Perspectives. London: Centre for Information on Language Teaching and Research

Hurrell, A. and Satchwell, P. (eds) (1996) Reflections on Modern Languages in Primary Education: Six UK case studies. London: Centre for Information on Language Teaching and Research 
Johnstone, R. (1991) "Foreign language in primary schools - evaluating the National Pilot Projects in Scotland." Language Learning Journal 4, pp. 36-8

Johnstone, R. (1994) Teaching Modern Languages at Primary School: Approaches and implications. Scottish Council for Research in Education

Lawton, J. G. (1996) "Modern languages in the primary school: investigating present practice." Language Learning Journal 13, pp. 2-5

Martin, C. (2000) "Modern foreign languages at primary school: a three-pronged approach?" Language Learning Journal 22, pp. 5-10
The Nuffield Foundation (2000) Languages: The next generation. The Nuffield Foundation: London

The Nuffield Foundation (2002) Response from the Steering Group of the Nuffield Languages Programme to the Consultation Document: 14-19: extending opportunities, raising standards. www.nuffieldfoundation.org

QCA (2004) A Scheme of Work for KS2 MFL. QCA: London

Sharpe, K. (2001) Modern Foreign Languages in the Primary School: The what, why \& how of early $M F L$ teaching. Kogan Page Ltd: London; Stylus Publishing Inc: Sterling, VA

\section{NOTES FOR CONTRIBUTORS}

\section{Contributions}

The Editors welcome previously unpublished articles, reports and other contributions which will further the cause of the learning and teaching of languages. These contributions are normally expected to fall into one of the following categories, although contributions of different lengths will also be considered:

(a) Articles or reports of about 3000 to 5000 words. (Longer pieces may be considered subject to prior consultation with the editors.)

(b) Shorter articles of up to 1000 words that might include items of information, notes on innovative classroom practice and discussion points (including those arising from previous articles).

An abstract of 200-250 words should accompany articles of 3000 to 5000 words and an abstract of approximately 100 words should accompany those of 1000 words.

Articles should be written in English and may deal with any aspect of FL teaching and learning, FL teacher education, contemporary language, literature and culture. Previously unpublished photocopiable classroom material to accompany the contribution (a worksheet, for example) is particularly welcome.

\section{Presentation}

Contributions must be fully formatted, typed with double spacing and sent in on disk or as an email attachment (MS Word preferred), accompanied by 3 copies on paper and an address for correspondence. These should be presented anonymously for review purposes, carrying no indication of the author's name or place of employment. The latter details should be given in a covering letter. Remember to keep a copy of the article for yourself. Please give your article one title only, not a title and a sub-title, but do feel free to divide it up with (short) sub-headings.

If you quote references or sources, please give full details using the Harvard system, e.g. Barber, C. (1993) The English Language: a historical introduction. Cambridge: CUP. In the text the author's name, year of publication and page number where relevant should be quoted in brackets, e.g. (Barber, 1993: 27).

\section{Copyright}

Authors are requested to seek copyright permission for any material they use from external sources before submitting their article and should discuss this, if it arises, with the Editors. If the article is accepted into the Journal, copyright will pass to ALL (although all other copyrighted sources will be acknowledged).

We welcome articles from new authors. All articles are refereed, and authors may be offered constructive feedback in order to support them in meeting the required standards. 